\title{
Pobreza y modelo macroeconómico neoliberal. Algunas contradicciones
}

\section{Roberto Soto Esquivel}

Las politicas públicas implementadas a partir del modelo neoliberal sólo han ampliado los niveles de pobreza y los márgenes de desigualdad social, debido a que son programas asistenciales o paternalistas, que sólo administran los problemas, pero no los combaten. El modelo económico vigente permite la correlación en un solo sentido, entre crecimiento de pobreza (falta de desarrollo humano) y nivel de producto (crecimiento económico), es decir, a un mayor nivel del pib, mayor pobreza, pero a un menor nivel del producto, mayor pobreza.

Alejamiento estatal

DEL DESARROLLO HUMANO

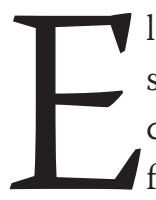

1 modelo económico neoliberal vigente en diversos países de América Latina y el Caribe (ALyc) desalienta la participación estatal que no beneficia al gran capital productivo y financiero. Al considerar al Estado como ineficiente, el sector privado -nacional y extranjero- - toma las principaes decisiones. Como resultado, decae el bienestar económico (empleo e ingreso dignos) y social (pobreza y desigualdad); además entran en contradicción los lineamientos de política económica y de combate a la pobreza, éstos últimos propuestos por instancias como el Programa de las Naciones Unidades para el Desarrollo (PNUD). ${ }^{1}$

La actual crisis económica pone en evidencia cómo el modelo ha incrementado los niveles de desigualdad, pobreza y contracción del ingreso, principalmente en ALyc. El modelo neoliberal postula que el mercado debe ser el regulador de la economía, pues las entidades pú- 
El resultado es el deterioro de la capacidad productiva y un insostenible nivel de consumo, el incremento de la pobreza y el desempleo. Los niveles de bienestar e igualdad se han deteriorado desde los años ochenta. Es decir, el neoliberalismo fragmentó el vínculo entre la generación del bienestar económico (empleo e ingreso dignos) y el bienestar social (pobreza y desigualdad), propiciando el aislamiento de la sociedad

socioculturales. Lo anterior es preocupante porque el modelo puede subsistir a cualquier nivel de pobreza y desigualdad.

Luego de tres décadas, el nivel de crecimiento de la producción ha sido moderado. ALyC creció por encima de $6 \%$ sólo en tres años, 1980, 2004 y 2010. El promedio del periodo 1994-2003 fue de 2.5\%; insuficiente para generar condiciones de estabilidad y desarrollo. En 1990 se tuvo una inflación de 478\%, para 2012 se espera que alcance un nivel de menos de $6.4 \%$, promedio regional.

La tasa de desempleo de la región a 2009 fue de $8.4 \%$. Aunque este valor creció aún más, si se considera a los que se encuentran en un rango de edad de 15 a 34 años, situándose en $12.35 \%$. Para las mujeres ubicadas en este rango, la tasa de desempleo aumentó a 14.9\%. La mayoría de los trabajadores ocupados con los niveles de ingreso más bajo labora en los sectores de baja productividad; el 22\% de ellos realiza aportes a la seguridad social y sólo $24 \%$ cuenta con seguridad social. Para la Comisión Económica para América Latina y el Caribe (CEPAL), ${ }^{3}$ los elevados niveles de subempleo y empleo informal que existen en la región son la expresión más visible de la heterogeneidad y una fuente muy importante de inequidad. Y si bien los niveles de pobreza han disminuido en forma moderada (30.4\% en 2011), la tasa de indigencia ha aumentado debido a factores como el alza del precio de los alimentos. Es decir, los resultados macroeconómico «favorables» o «exitosos» (al menos en la visión oficial) no corresponden con el impacto social demoledor.

\section{Contradicciones del Modelo y SOLUCIÓN A LA POBREZA}

La falta de empleo, con salarios dignos, es un problema que amerita una solución inmedia-

El resultado es el deterioro de la capacidad productiva y un insostenible nivel de consumo, el incremento de la pobreza y el desempleo. ta por razones de justicia social. La política económica se ha orientado a satisfacer la demanda externa de bienes y servicios, donde el Estado ha jugado un papel mínimo para impulsar el desarrollo, al menos como creador de empleo a través de las entidades públicas.

La conformación de outsourcing, es decir, empresas dedicadas a la subcontratación, forma parte del proceso de reformas estructurales que minan las condiciones laborales de los trabajadores. Por tanto, el incremento de niveles de desempleo, acompañado de empleos temporales o permanentes, en condiciones precarias, son características de este proceso. Esto provoca consecuencias sociales muy importantes como la pérdida de la capacidad de compra (disminución del salario real) y la disminución del mercado interno. El escenario se agrava con la llamada reforma laboral impulsada en diversos países de ALyC, como parte de las reformas estructurales que incluyen ${ }^{4}$ flexibilizar el mercado laborar, institucionalizar el trabajo temporal, eliminar o control de los derechos y prestaciones de los trabajadores.

Asimismo, el problema del financiamiento productivo es fundamental. El modelo de política económica contempla disponer de recursos suficientes para hacer frente a los compromisos de la deuda externa, por encima de la satisfacción de las necesidades sociales y de la promoción del desarrollo productivo nacional. ALyC enfrenta una fuerte necesidad de financiamiento productivo que le permita alcanzar un desarrollo humano sostenible y sustentable. El modelo neoliberal sugiere que éste debe provenir de la inversión extranjera directa, bajo un esquema de estabilidad macroeconómica (inflación controlada, equilibrio o superávit fiscal y comercial) que permita alcanzar la modernización productiva.

La evidencia ha demostrado que esto no ha funcionado, pues si bien algunas naciones experimentan cambios en su forma de gobierno, contraria al neoliberalismo, los bancos centrales están en manos de la oligarquía financiera, arropada en la famosa independencia de la autoridad central, la cual mantiene el control de la política financiera, monetaria y fiscal, con lo que dificulta el proceso de financiamiento, por lo que continúan las fallas estructurales que bloquean el desarrollo, tales como la dependencia económica y financiera con respecto a los países desarrollados (centro-periferia), la falta de un 
mercado interno que genere efectos multiplicadores y la estructura productiva terciarizada y reprimarizada.

Las políticas del Consenso de Washington cambiaron las estructuras de las economías de la región, en particular el retiro paulatino de la banca pública en el financiamiento de la actividad productiva. ${ }^{5}$ Los planes de estabilización del FMI tienen los siguientes propósitos: ${ }^{6}$ desarticular el modelo de desarrollo creado a partir de la década de los cincuenta, hacer competir a las empresas nacionales con las extranjeras y expandir en forma moderada el control de los activos productivos y financieros de los conglomerados trasnacionales. El resultado de estas políticas ha sido la agudización de la crisis y su consecuente efecto en el desarrollo de las naciones.

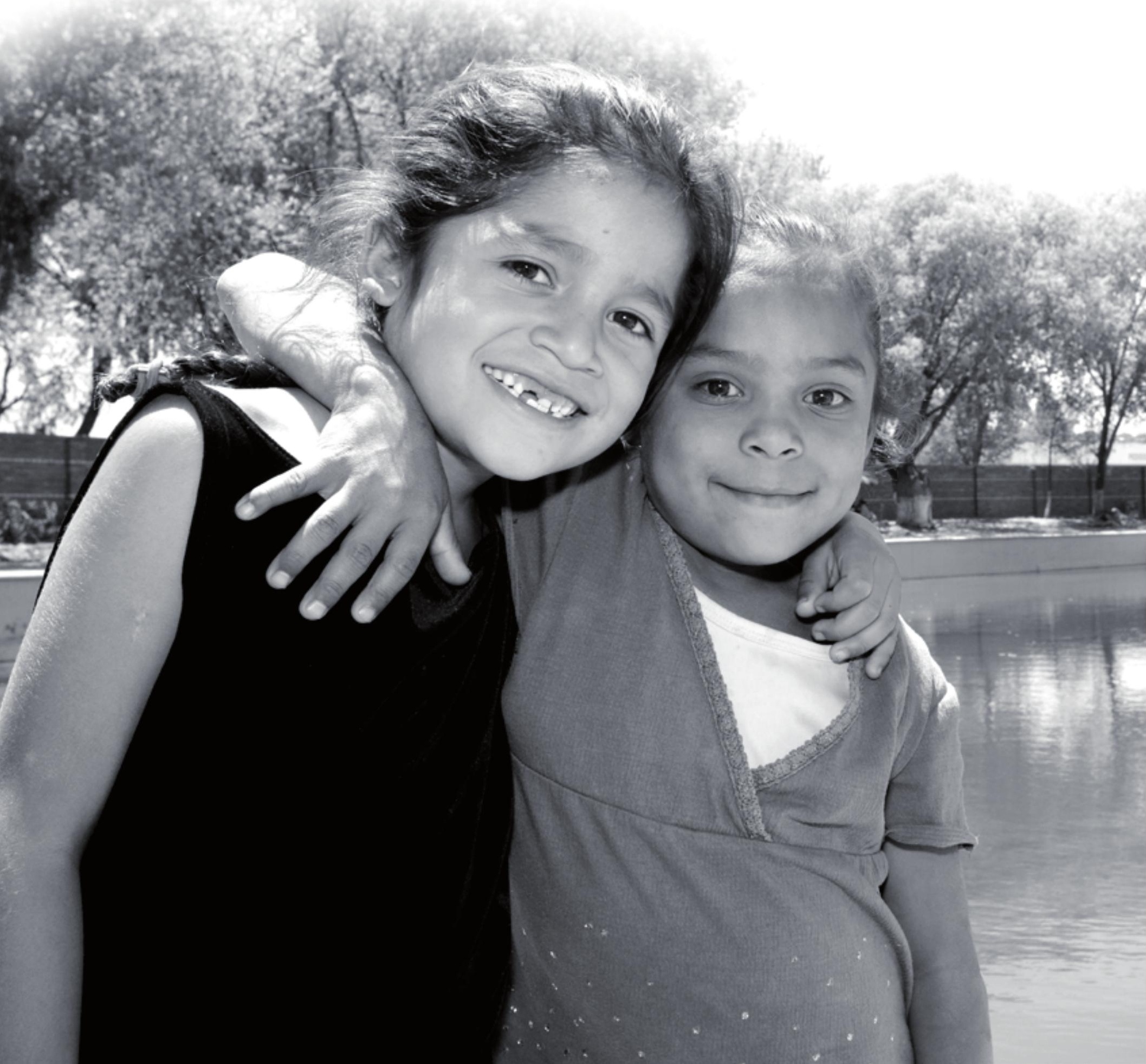




\section{CONCLUSIÓN}

Para combatir la pobreza, el PNUD ha sugerido implementar las siguientes políticas, no obstante la contraposición del FMI y BM en el ámbito macroeconómico: ${ }^{7}$ a) ante la falta de oportunidades, ejecutar obra pública en infraestructura y generar tecnologías apropiadas, aunque los organismos financieros recomiendan reducir el gasto público; $b$ ) en el escenario del desarrollo desigual, crear áreas de viviendas cercanas a los lugares de trabajo, fomentar un mejor y mayor transporte público, pero los financieros recomienda políticas generadoras de recursos para pagar los intereses de la deuda externa, principalmente a bancos estadounidenses, y $c$ ) en lugar de políticas equivocadas que generan pobreza, fomentar las coinversiones entre ciudadanía y gobierno, eliminar subsidios a favor de los poseedores de los mayores recursos, adoptar políticas de salud y educación que aminoren el rezago, pero al mismo tiempo se obliga a adoptar políticas que eliminen subsidios a sectores clave del sector social.

Ante el escenario descrito, es difícil crear un mercado interno dinámico que fortalezca la economía y genere empleo con salarios dignos, permitiendo alcanzar el desarrollo humano pleno. Es por ello que se vuelve imperativo modificar la política económica en los rubros financiero, monetario y fiscal. Pero también se puede y se debe crear una política pública que busque compensar el empleo que no es generado por el sector privado, porque sólo mediante éste se puede superar la pobreza y la desigualdad, y no mediante políticas paternalistas y asistenciales que únicamente la administran.

Por tanto, es necesario replantear el modelo y las políticas económicas que adoptan los países, sustituyéndolas por aquéllas donde el Estado cumpla las funciones de generar desarrollo humano y crecimiento sostenido y sustentable; para ello, debe dotarse a la población de empleo y salario dignos, según sus necesidades y capacidades.

Para lograr lo anterior, es necesario que los países tengan autodeterminación. Como condición necesaria para el desarrollo, deben plantear un modelo que se aleje de la subordinación global (globalización que postula poca actividad del Estado, favoreciendo la privatización y la liberalización). El Estado debe generar los empleos que se requieran para poder compensar los que el sector privado no genera, para ello debe cambiar la política económica - en particular, la fiscal y la financiera- para captar recursos y fomentar programas públicos de empleo y unidades económicas productivas y generadoras de empleo. Entonces podra reducirse al mínimo, sin simulaciones, la problemática de pobreza y desigualdad.

La falta de
empleo, con
salarios dignos,
es un problema
que amerita
una solución
inmediata por
razones de
justicia social.

\section{Notas}

1 Guillermo Foladori, «Avances y limitaciones de la sustentabilidad social» en Economía, sociedad y territorio, El Colegio Mexiquense, volumen III, número 12, julio-diciembre, 2002.

2 Robert Guttmann, «Introducción al capitalismo conducido por las finanzas», enero-abril, México, IIEC-UNAM, 2009, «http:// www.olafinanciera.unam.mx> (consultado: 05/03/2012).

3 CEPAL, Eslabones de la desigualdad, Chile, junio, 2012.

4 Arturo Guillén, «México: alternancia política, estancamiento económico y proyecto nacional de desarrollo» en José Luis Calva, Políticas macroeconómicas para el desarrollo sostenido, México, Juan Pablo editores, volumen 4, 2012
5 Gregorio Vidal y Wesley Marshall, «Sistema financiero, crédito externo y crisis global en América Latina: ¿fin de un modelo o incremento del despojo?» en Alicia Girón y José Déniz, Crisis financiera. Nuevas manías viejos pánicos, Madrid, 2010, pp. 47-68.

6 Alicia Girón, «Crisis y sistemas financieros en América Latina: Argentina, Brasil y México», en Alicia Girón y José Déniz, op. cit., pp. 111-124.

7 Guillermo Foladori, «Avances y limitaciones de la sustentabilidad social» en Economía, sociedad y territorio, El Colegio Mexiquense, volumen III, número 12, julio-diciembre, 2002. 